\title{
Composite catalysts for the catalytic processing of fuel oil
}

\author{
Tatyana Shakiyeva ${ }^{1}$, Larissa Sassykova ${ }^{1}$, Anastassiya Khamlenko $^{1-}$, Binara Dossumova ${ }^{1}$, \\ Albina Sassykova ${ }^{2}$, Albina Muratova ${ }^{1}$, Madina Zhumagali ${ }^{1}$, Nurbubi Zhakirova ${ }^{1}$, and \\ Tleutai Abildin ${ }^{1}$ \\ ${ }^{1}$ Al-Farabi Kazakh National University, 050040 Almaty, Kazakhstan \\ ${ }^{2}$ Almaty College of Economics and Law, 050004 Almaty, Kazakhstan
}

\begin{abstract}
The paper describes the catalytic cracking of heavy petroleum feedstock on catalysts based natural Taizhuzgen zeolite and Narynkol clay (Kazakhstan). Catalytic cracking was studied on fuel oil of the M-100 brand taken from the LLP Pavlodar Oil Chemistry Refinery (Kazakhstan). Air was added into the reaction medium. It was found that under optimal conditions, the conversion of the heavy residue of M-100 fuel oil reaches $46.2 \%$, when cracking the initial fuel oil, the yield of the middle distillate fraction is 85.7 wt. $\%$ due to the content of $41.1 \mathrm{wt}$. \% residual light gas oil in the resulting products. The optimal composite catalyst allows carry out the cracking of heavy oil residues without preliminary purification and with a high degree of conversion to diesel fraction.
\end{abstract}

\section{Introduction}

Despite the growing interest in non-traditional energy sources, in the next 2-3 decades, the largest consumption will also remain for natural energy carriers. Their share will remain over $80-85 \%$. It is obvious that the total consumption and energy production a dominant position will still remain for oil, second - gas, third for coal.

Increasing the depth of oil refining is the main direction of modern global oil refining and is associated with the development and implementation of flexible technological schemes and promising high-intensity and environmentally friendly thermocatalytic and hydrogenating processes [1-3]. The advantages of using oxidative cracking to obtain quality fuel have been described in a number of works $[4,5]$. Catalytic cracking with the addition of traces of air to the reaction medium is characterized by high technical and economic efficiency of the process, lower energy consumption. In the process of oxidative catalytic cracking, a balance is maintained between the exothermic oxidation reactions and the endothermic reactions of the catalytic cracking itself, there is no coke and a low yield of gaseous products is observed. As a rule, most of the sulfur is contained in the cracked residue (bitumen), and the sulfur content in the light fractions is minimal. In addition, the yield of light fractions of good quality with higher octane and cetane numbers increases [6, 7]. It is very important that there is no need for preliminary preparation of raw materials for

- Corresponding author: khamlenko.a.a@mail.ru 
the removal of sulfur in order to increase the yield of light fractions and reduce the formation of coke $[8,9]$.

It should be taken into account that for modern catalysts for cracking residual raw materials, which use ultra-stable forms of zeolites, high selectivity for gasoline does not correlate with the maximum cracking activity. A possible way to reduce the cost of catalysts is to develop them on the basis of natural zeolites. The most effective way to increase the efficiency of catalytic cracking plants is to prepare the raw materials in a special way.

In this work, the catalytic cracking of heavy petroleum feedstock on catalysts synthesized on the basis of natural zeolite and clay from fields in Kazakhstan has been studied. Air microadditives were added into the reaction medium. The work established the effect of air on the route of reactions occurring during cracking and the relationship between the parameters of oxidative catalytic cracking and the degree of conversion of heavy oil feedstock hydrocarbons into light products.

\section{Experimental part}

The cracking process was carried out both in an inert atmosphere without a catalyst (i.e. under thermal cracking conditions); and in the presence of a catalyst, in an inert atmosphere in a $0.2 \mathrm{wt} . \%$ suspension of a finely dispersed composite (i.e. under conditions of catalytic cracking). The efficiency of the catalyst was tested by feeding a suspension of the catalyst in fuel oil and, at the same time, air into the reactor (that is, under conditions of oxidative catalytic cracking). The installation of oxidative catalytic cracking of fuel oil is shown in Fig.1.

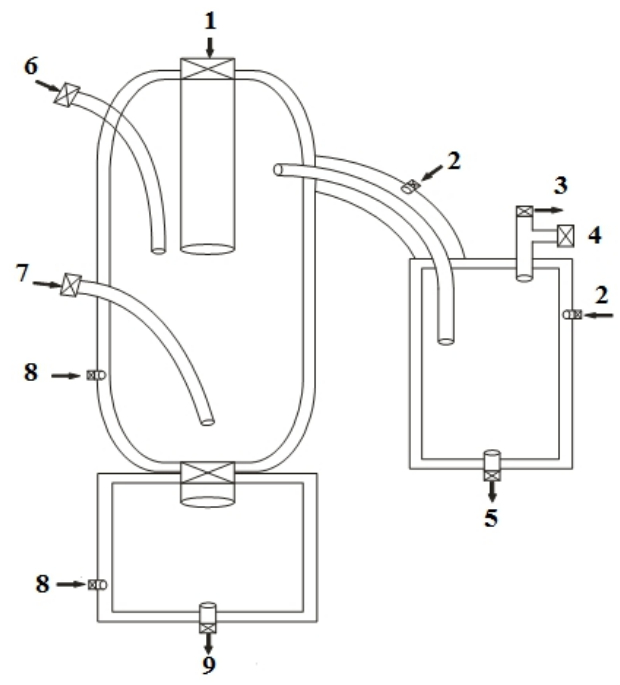

Fig. 1. Schematic diagram of the reactor of oxidative catalytic cracking of fuel oil: 1 -catalyst suspension in fuel oil; 2 - refrigerant; 3 - gas sent for combustion; 4 - ejector; 5 - liquid products sent to the hydro-refining unit; 6 - air; 7 - inert gas; 8 - heat carrier; 9 - tar sent to the warehouse.

Catalytic cracking was studied on fuel oil of the M-100 brand taken from the LLP Pavlodar Oil Chemistry Refinery (Kazakhstan). The plant in Pavlodar processes West Siberian oil (Russia) according to the fuel option and provides a refining depth of up to $85 \%$, which corresponds to the level of the best producers of oil products.

The activity of the catalyst was evaluated by feeding a catalyst suspension into the reactor in fuel oil and simultaneously with air (that is, under conditions of redox-catalytic 
cracking). The analysis of gaseous cracking products was carried out on a gas chromatograph with a flame ionization detector. The spectra of the sample were written on the JNN-ECA 400 spectrometer of the company "Jeol" (Japan) at room temperature using $\mathrm{CDCl}_{3}$ solvent. The operating frequency of the spectrometer is 400 on ${ }^{1} \mathrm{H}$ and $100 \mathrm{MHz}$ on ${ }^{13} \mathrm{C}$ cores. Chemical shifts are measured relative to the signals of residual protons or carbon atoms of deuterated chloroform.

The catalysts used were prepared on the basis of Kazakhstan's natural raw materials: zeolite from the Taizhuzgen field and clay from the Narynkol field. The phase composition of the catalysts was determined using a DRON-4 diffractometer.

\section{Results and discussion}

The proton spectrum of initial fuel oil (Fig.2-3) contains ${ }^{1} \mathrm{H}$ signals of paraffinic, naphthenic and aromatic compounds, which are the main components of the mixture. Methyl proton signals from saturated hydrocarbons were detected as a broadened singlet at $0.90 \mathrm{ppm}$. High-intensity signal with a chemical shift of $1.28 \mathrm{ppm}$ indicates a significant content of protons of methylene groups of aliphatic cyclic and acyclic hydrocarbons. A small amount of $\mathrm{CH}_{3}$ groups was noted in the $\alpha$-position to the aromatic ring $(\delta=2.30-2.63$ ppm). In the range of 2.70-4.50 ppm probably the resonance of protons of the $\mathrm{CH}_{2}$ and $\mathrm{CH}$ groups in the $\alpha$-position of aromatic compounds [2].

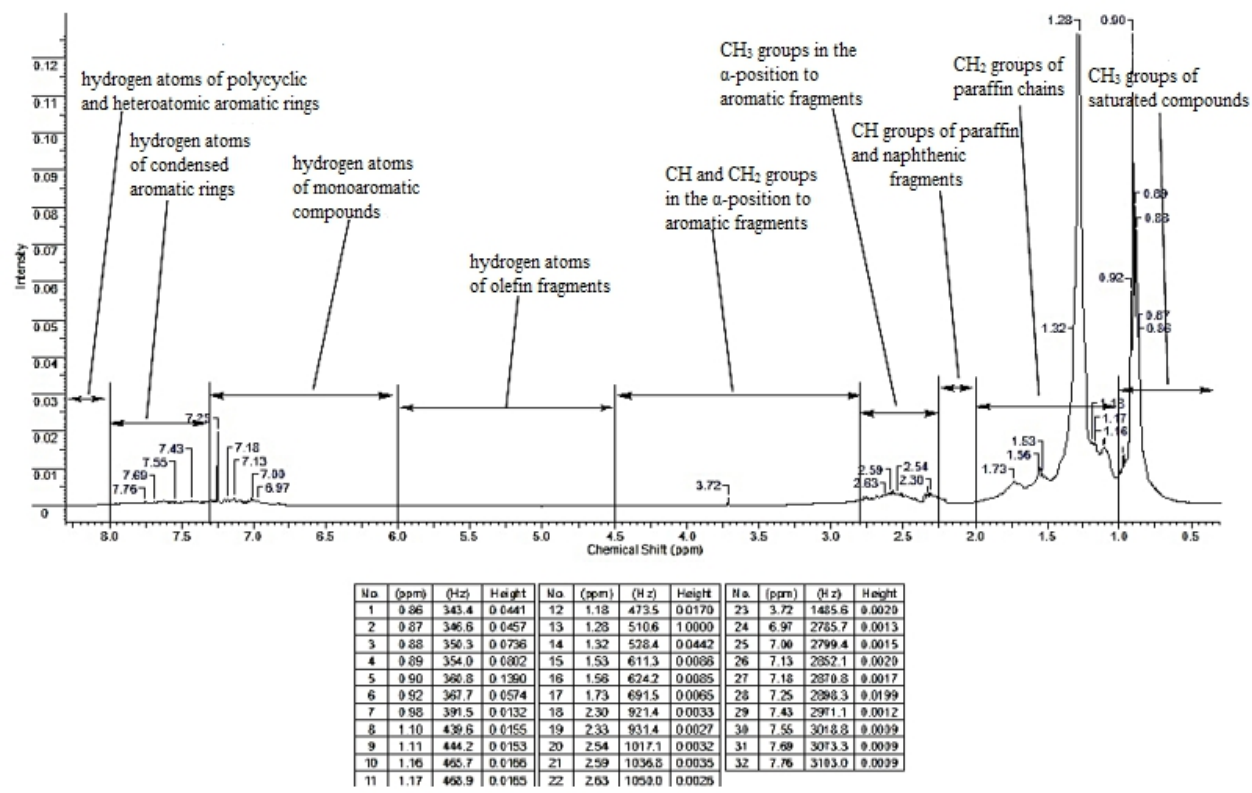

Fig. 2. ${ }^{1} \mathrm{H}$ NMR spectrum of initial fuel oil. 


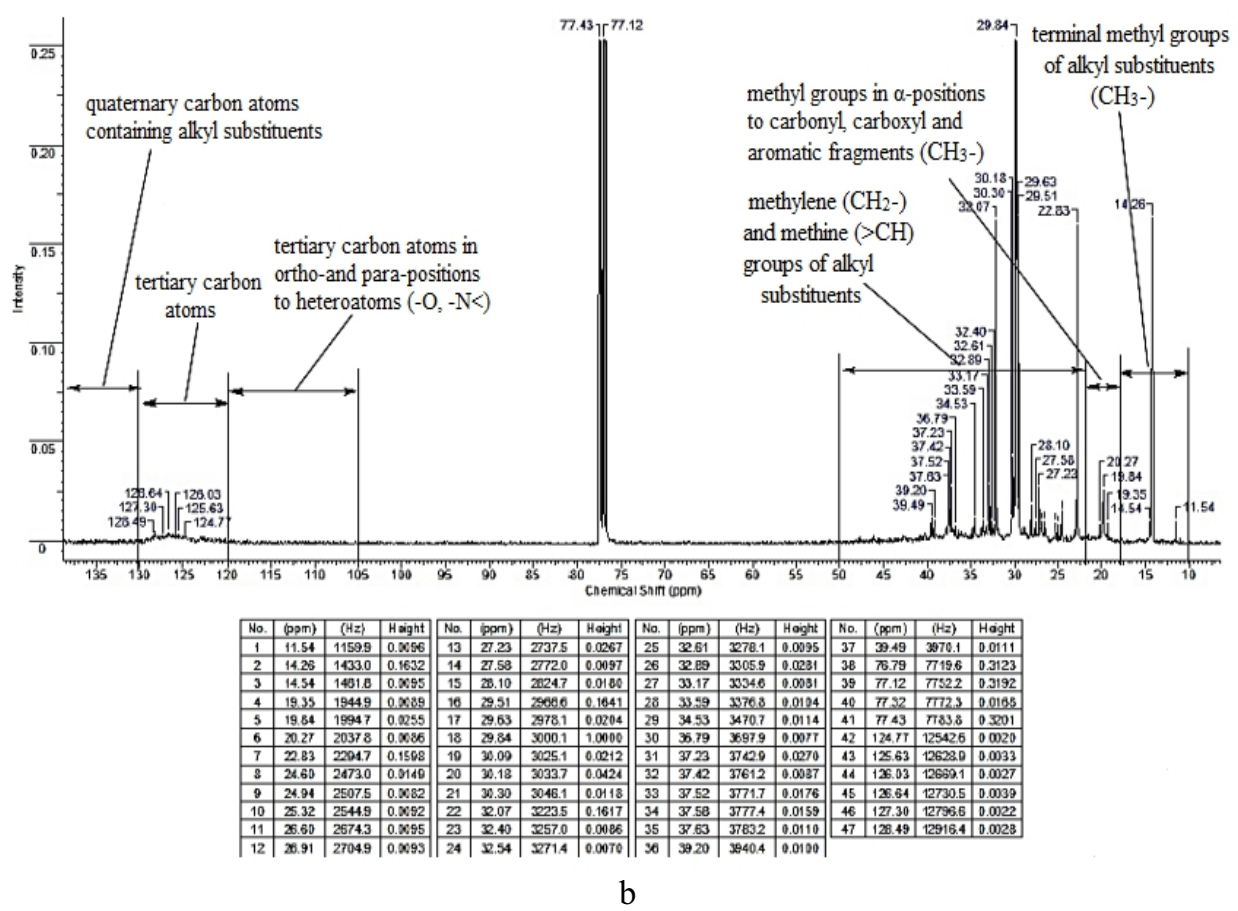

Fig. 3. ${ }^{13} \mathrm{C}$ NMR spectrum of initial fuel oil.

Chemical composition of catalysts and results of X-ray phase analysis of catalysts prepared are presented in Table 1.

Table 1. Results of X-ray phase analysis of catalysts for cracking fuel oil from the LLP Pavlodar Oil Chemistry Refinery (the numbering of minerals is given in decreasing order of their concentration in the analyzed samples).

\begin{tabular}{|c|c|c|c|c|}
\hline \multirow[b]{2}{*}{ Mineral composition } & \multicolumn{2}{|c|}{ unactivated } & \multicolumn{2}{|c|}{ optimal } \\
\hline & $\begin{array}{c}\text { before } \\
\text { calcination }\end{array}$ & $\begin{array}{c}\text { after } \\
\text { calcination }\end{array}$ & $\begin{array}{c}\text { before } \\
\text { calcination }\end{array}$ & $\begin{array}{c}\text { after } \\
\text { calcination }\end{array}$ \\
\hline Kaolinite $2\left[\mathrm{Al}_{2} \mathrm{Si}_{2} \mathrm{O}_{5}(\mathrm{OH})_{4}\right]$ & 1 & 1 & 1 & 1 \\
\hline Quartz $\mathrm{SiO}_{2}$ & 2 & 2 & 2 & 2 \\
\hline Potassium feldspar $\mathrm{KAlSi}_{3} \mathrm{O}_{8}$ & 3 & 4 & 3 & 5 \\
\hline Feldspar $\mathrm{NaAlSi}_{3} \mathrm{O}_{6}$ & 4 & 3 & 4 & 3 \\
\hline $\begin{array}{l}\text { The cell parameters } \\
\text { of magnesioferrite } \\
\text { zeolite structure }\end{array}$ & absent & absent & absent & $\begin{array}{c}\mathrm{A}_{0}=11.39 \AA \\
\mathrm{B}_{0}=7.37 \AA \\
\mathrm{C}_{0}=5.62 \AA \\
\beta=157.9\end{array}$ \\
\hline
\end{tabular}

The results obtained in the cracking of M-100 fuel oil and its heavy residue under cracking conditions are presented in Table 2. It was found that the yield of gaseous products and gasoline is very low and does not depend on the process conditions, as well as the type of cracked feedstock. It is obvious that in all cases light products are formed as a result of deep destruction of high molecular weight hydrocarbons of the heavy residue. 
Table 2. Cracking of M-100 fuel oil and its heavy residue (suspension $=1.0 \mathrm{~h}^{-1}, \mathrm{~T}=470{ }^{\circ} \mathrm{C}$ ).

\begin{tabular}{|c|c|c|c|c|c|c|c|c|c|}
\hline \multirow{2}{*}{\begin{tabular}{|c|} 
Catalyst \\
concentration, \\
wt. $\%$
\end{tabular}} & \multirow{2}{*}{$\begin{array}{c}\omega_{\text {air }}, \\
\mathrm{h}^{-1}\end{array}$} & \multicolumn{7}{|c|}{ Cracking product yield, wt. $\%$} & \multirow[t]{2}{*}{ Total } \\
\hline & & gas & gasoline & $\begin{array}{c}\text { light gas } \\
\text { oil } \\
185-340^{\circ} \mathrm{C}\end{array}$ & $\begin{array}{c}\text { light gas } \\
\text { oil } \\
340-350^{\circ} \mathrm{C}\end{array}$ & \begin{tabular}{|c|} 
total \\
light \\
gas oil \\
\end{tabular} & $\begin{array}{l}\text { heavy } \\
\text { residue }\end{array}$ & losses & \\
\hline \multicolumn{10}{|c|}{ Fuel oil } \\
\hline 0 & 0 & 0.9 & 1.2 & 25.8 & 13.7 & 39.5 & 58.4 & 0 & 100.0 \\
\hline 0 & 0.15 & 1.1 & 1.0 & 30.1 & 18.5 & 48.6 & 49.3 & 0 & 100.0 \\
\hline 0.2 & 0 & 1.4 & 0.9 & 51.6 & 19.8 & 71.4 & 26.3 & 0 & 100.0 \\
\hline 0.2 & 0.15 & 0.8 & 1.1 & 52.5 & 33.2 & 85.7 & 11.9 & 0.5 & 100.0 \\
\hline \multicolumn{10}{|c|}{ Heavy residue } \\
\hline 0 & 0 & 0.6 & 0.8 & 0.8 & 1.2 & 2.0 & 96.6 & 0 & 100.0 \\
\hline 0 & 0.15 & 1.1 & 1.0 & 4.1 & 3.7 & 7.8 & 90.1 & 0 & 100.0 \\
\hline 0.2 & 0 & 1.4 & 1.2 & 15.3 & 13.7 & 29.0 & 68.4 & 0 & 100.0 \\
\hline 0.2 & 0.15 & 2.8 & 1.3 & 21.9 & 20.2 & 42.1 & 53.8 & 0 & 100.0 \\
\hline
\end{tabular}

The optimal yield of light gas oil during cracking both in an inert atmosphere and in the presence of trace amounts of air is a catalyst containing $14 \mathrm{wt} . \%$ of activated natural zeolite Taizhuzgen. The formation of the zeolite structure apparently occurs due to the optimal ratio in the $14 \%$ zeolite-containing composite of the phases of calcite, mixed-layer clay mineral and gypsum interacting with each other at the stage of heat treatment with the formation of scolecite.

It was revealed that with an increase in the volumetric velocity of the introduction of air and cracked feedstock, but with the addition of a catalyst, sulfur-containing hydrocarbons are apparently oxidized. This is evidenced by the disappearance of absorption bands at 747 $\mathrm{cm}^{-1}$, which characterize the stretching vibrations of the C-S bond, and the appearance of an absorption band at $940 \mathrm{~cm}^{-1}$, indicating the presence of sulfoxides in the sample under study. Under the conditions of catalytic cracking in an inert atmosphere, sulfur compounds were not detected in the resulting product. Therefore, they are not oxidized, and the catalyst promotes their destruction and removal from the final product.

As a result of catalytic cracking, the yield of light gas oil in comparison with oxidative thermal oil increases by $21.2 \mathrm{wt} . \%$, and with an oxidizing catalytic addition by $13.1 \mathrm{wt} . \%$. In the most suitable conditions the conversion of the heavy residue of fuel oil M- 100 reaches $46.2 \%$, and when cracking the initial fuel oil, the yield of the middle distillate fraction is $85.7 \mathrm{wt}$ \% due to the content of residual light gas oil in the resulting products. According to gas chromatography-mass spectrometric analysis the formation of $\mathrm{C}_{7}-\mathrm{C}_{12}$ hydrocarbons occurs exclusively due to the symmetric decomposition of $\mathrm{C}_{14}-\mathrm{C}_{24}$ paraffins, since the products of this reaction are the corresponding $\alpha$-olefins and n-alkanes.

The obtained results suggest the mechanism of the reaction of oxidative cracking of heavy oil residues in a low-percentage suspension of an activated composite catalyst from natural components. It is obvious that the catalytic destruction of hydrocarbon molecules occurs through the formation of free radicals, so the introduction of air into the reaction zone, the oxygen of which is the initiator of this process, significantly increases the yield of the average distillate fraction.

\section{Conclusions}

The optimal composite catalyst based on natural raw materials allows cracking of heavy oil residues without preliminary cleaning and with a high degree of conversion to the diesel fraction. Air additives contribute to a deeper decomposition of the hydrocarbons of the 
source material. As a result of the cracking reactions of M-100 fuel oil, the resulting light gas oil contains a significant amount of $\alpha$-olefins, which can be a valuable raw material for the production of synthetic additives and oils.

\section{References}

1. J.G. Speight, Catal. Today 98, 55 (2004)

2. R. Kh. Ibrasheva, V.S. Yemelyanova, L.R. Sassykova, U. N. Dzhatkambayeva, T.V. Shakiyeva, B.T. Dossumova, N.K. Zhakirova, S. Sendilvelan, T. M. Seilkhanov, Rasayan J. Chem, 13, 2370 (2020)

3. Y. Tanimoto, H. Tanaka, Y. Fujiwara, M. Fujiwara, J. Phys. Chem. A 102, 5611 (1998)

4. E. A. Guseinova, L. A. Mursalova, N. N. Bagirova, K. Yu. Adzhamov, Pet. Chem. 59, 180 (2019)

5. T.V. Shakiyeva, L.R. Sassykova, U. N. Dzhatkambayeva, A.A. Khamlenko, N.K. Zhakirova, A.A. Batyrbayeva, R. N. Azhigulova, Sh. N. Kubekova, Zh. M.

Zhaxibayeva, M. A. Kozhaisakova, L. A. Zhusupova, S. Sendilvelan, K. Bhaskar, Rasayan J. Chem. 14, 1056 (2021)

6. X. Liu, W. Li, H. Zhu, Q. Ge, Y. Chen, H. Xu, Catal. Lett. 94, 31 (2004)

7. C. Boyadjian, L. Lefferts, Eur. J. Inorg. Chem. 19, 1956 (2018)

8. N.A. Pivovarova, Pet. Chem. 59, 727 (2019)

9. G. Song, D.-H. Wang, Zh. Zhang, M. Liu, Q. Xu, D.-Z. Zhao, Ultrason. Sonochem. 48, 103 (2018) 